\title{
Valorisation of tomato wastes for development of nutrient-rich antioxidant ingredients: A sustainable approach towards the needs of the today's society
}

\author{
José Pinela ${ }^{\mathrm{a}, \mathrm{b}}$, M.A. Prieto ${ }^{\mathrm{a}, \mathrm{c}, *}$, Maria Filomena Barreiro ${ }^{\mathrm{d}}$, Ana Maria Carvalho ${ }^{\mathrm{a}}$, M. Beatriz P.P. Oliveira ${ }^{\mathrm{b}}$, \\ Thomas P. Curran ${ }^{\mathrm{e}}$, Isabel C.F.R. Ferreira ${ }^{\mathrm{a}, *}$ \\ a Mountain Research Centre (CIMO), ESA, Polytechnic Institute of Bragança, Campus de Santa Apolónia, 1172, $5300-253$ Bragança, Portugal \\ ${ }^{\mathrm{b}}$ REQUIMTE/LAQV, Faculty of Pharmacy, University of Porto, Rua Jorge Viterbo Ferreira, $n^{\circ} 228,4050$-313 Porto, Portugal \\ c Nutrition and Bromatology Group, Faculty of Food Science and Technology, University of Vigo, Ourense Campus, E32004 Ourense, Spain

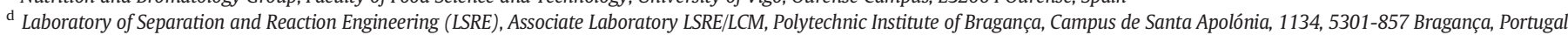 \\ e UCD School of Biosystems and Food Engineering, University College Dublin, Belfield, Dublin 4, Ireland
}

\section{A R T I C L E I N F O}

\section{Article history:}

Received 20 December 2016

Received in revised form 31 January 2017

Accepted 8 February 2017

Available online 11 February 2017

\section{Keywords:}

Tomato waste valorisation

Microwave-assisted extraction

Nutritional ingredients

Antioxidant activity

Response surface methodology

\begin{abstract}
A B S T R A C T
Nutrient-rich antioxidant ingredients were produced from tomato fruit wastes using a microwave-assisted extraction (MAE) process. Different conditions of extraction time $(t)$, temperature $(T)$, ethanol concentration $(E t)$ and solid/liquid ratio $(\mathrm{S} / \mathrm{L})$ were combined in a circumscribed central composite design and optimized by response surface methodology. The model was statistically validated and used for prediction in the experimental range. Under the global optimal MAE conditions ( $t=20 \mathrm{~min}, T=180^{\circ} \mathrm{C}, E t=47.4 \%$ and $\mathrm{S} / \mathrm{L}=45 \mathrm{~g} / \mathrm{L}$ ), it was possible to obtain an extraction yield of $75.5 \%$ and ingredients with high levels of sugars, proteins, phenolics, and flavonoids, and interesting antioxidant properties measured via ABTS ${ }^{+}{ }^{+}$scavenging activity and oxidative haemolysis inhibition assay (OxHLIA). The antioxidant capacity of the extracts was lower compared to the one of commercial food additives. However, the sustainably developed ingredients may be used in the fortification and functionalisation of food, as well as for incorporation in feed products.

Industrial relevance: This study addresses current needs of the agri-food sector, namely the recycling of plant wastes and production of valuable extracts for the food/feed industry. A MAE process was developed and optimized to maximize the recovery of nutrients and antioxidants from tomato fruit wastes. The optimum processing conditions established in this study allowed a high extraction yield and reduced solvent consumption. MAE can be considered as a sustainable alternative to conventional extraction methods. These findings will contribute to promote a more sustainable bioeconomy in the agro-food sector.
\end{abstract}

(c) 2017 Elsevier Ltd. All rights reserved.

\section{Introduction}

The strict legislation for human health and environmental safety implemented today, and the emergence of novel methodologies for the extraction, fractionation, and recovery of biomolecules have caused great interest in plant-derived waste valorisation. Different kinds and amounts of agri-food wastes are produced within the food-supply chain, representing a disposal problem for the industry (FAO, 2013), but promising sources of nutrients and phytochemicals (Ravindran \&

Abbreviations: $t$, extraction time; $T$, temperature; Et, ethanol concentration; S/L, solid/ liquid ratio; PROT, total protein content; RS, reducing sugars; TFC, total flavonoid content; TPC, total phenolic content; TS, total sugars.

* Corresponding authors.

E-mail addresses: mprieto@ipb.pt (M.A. Prieto), iferreira@ipb.pt (I.C.F.R. Ferreira).
Jaiswal, 2016; Riggi \& Avola, 2008). Thus, the sustainable use of plantderived wastes for recovery of added-value compounds with potential application in the food, feed, biotechnological, and pharmaceutical industries may help to tackle the societal challenges of the 21st century.

The recovery of valuable molecules from agri-food wastes and its recycling inside the food chain as food ingredients can be carried out following the so-called " 5 -stages universal recovery process" (Galanakis, 2012, 2013). This holistic approach includes: (1) macroscopic pretreatment; (2) separation of macro- and micromolecules; (3) extraction; (4) purification/isolation; and (5) encapsulation or product formation (Galanakis, 2012). Recent trends on extraction, one of the most important steps of the recovery process, have focused on finding more efficient and green technologies that minimize the extraction time and solvent consumption. Among them, microwave-assisted extraction (MAE) (Albuquerque et al., 2017; Pinela, Prieto, Carvalho, et al., 2016b), ultrasound-assisted extraction (Albuquerque et al., 2017; 
Heleno et al., 2016), and extraction with electrotechnologies (such as pulsed electric fields, high-voltage electrical discharges and pulsed ohmic heating (Barba, Galanakis, Esteve, Frigola, \& Vorobiev, 2015; Galanakis, 2012, 2013; Roselló-Soto et al., 2015)) and pressurized liquids (Galanakis, 2013; Setyaningsih, Saputro, Palma, \& Barroso, 2016) generally meet these requirements. In the case of MAE, the microwaves energy heat the solvent and interacts directly with the free water molecules present inside the plant material, resulting in a rapid build-up of pressure within cells and a pressure-driven enhanced mass transfer of compounds into the solvent. This hot-spot technique has been indicated to achieve high yields of specific phytochemicals (Deng et al., 2015) and to minimize its degradation and the energy consumption (Strati \& Oreopoulou, 2014; Zhang, Yang, \& Wang, 2011).

Extraction processes are significantly affected by several factors (Albuquerque et al., 2017; Heleno et al., 2016; Pinela et al., 2016b; Wong et al., 2015). For its optimization, one-factor-at-a-time approaches do not evaluate interactive effects among variables and demand an increased number of experimental trials. However, these problems can be overcome using the response surface methodology (RSM), a collection of statistical and mathematical techniques based on the fit of a polynomial equation to the experimental data, which must describe the behaviour of a data set, with the aim of making statistical previsions (Bezerra, Santelli, Oliveira, Villar, \& Escaleira, 2008). When planning MAE experiments, it is also necessary to choose an appropriate experimental design. The circumscribed central composite design (CCCD) is a common RSM used and consists of a design with centre points and a group of axial points, also called star points, to estimate the process curvature (Box \& Hunter, 1957). It is also important to carry out preliminary studies to select relevant variables and centre the experimental domain.

Currently, there are large amounts of fresh tomato wastes resulting from the crop growing, as well as during packaging, processing, storage, and sale, which consist of plant remains, green fruits, turning fruits, red unmarketable fruits, and miscellaneous materials (Riggi \& Avola, 2008). In addition, losses resulting from a surplus production of this crop can also occur. The fruit contains large amounts of bioactive compounds (Barros et al., 2012; Pinela, Barros, Carvalho, \& Ferreira, 2012), which are involved in the reduced risk for chronic degenerative diseases induced by oxidative stress and inflammation, such as cardiovascular diseases and various types of cancer (Kim, Nam, \& Friedman, 2015; Li, Deng, Liu, Loewen, \& Tsao, 2014; Pinela, Oliveira, \& Ferreira, 2016c; Stajčić et al., 2015; Vilahur et al., 2014). Additionally, there is a growing demand by the food industry and consumers for the use of natural functional and nutritional ingredients in foods instead of chemically synthesized molecules (Carocho, Morales, \& Ferreira, 2015). Because of this, the tomato wastes are promising cheap resources to be recovered and recycled inside the food chain, in order to implement a sustainable strategy that addresses the current challenges of the industrialized world.

In this sense, this study aims the valorisation of fresh tomato fruit wastes by establishing a MAE protocol for production of nutritionally valuable ingredients with antioxidant properties based on a CCCD. In this approach, the levels of total sugars, reducing sugars, proteins, total phenolics, and total flavonoids were determined and used as dependent variables; as well as the antioxidant activity, evaluated through the ABTS and OxHLIA in vitro assays, which was compared with the results of typical commercial antioxidants used in the food industry.

\section{Material and methods}

\subsection{Equipment, standards and reagents}

Equipments: Microwave apparatus (Biotage ${ }^{\circledR}$ Initiator $^{+}$, Uppsala, Sweden) using closed high precision glass vials. Multiskan Spectrum
Microplate Photometer (Thermo Fisher Scientific, Inc., Shanghai, China) using 96-well polypropylene microplates.

Standards and reagents: ABTS (2,2'-azino-bis(3-ethylbenzothiazoline-6-sulfonic acid)), AAPH (2,2'-azobis(2-methylpropionamidine) dihydrochloride), trolox (6-hydroxy-2,5,7,8-tetramethylchroman-2carboxylic acid), BHA (butylated hydroxyanisole), BHT (butylated hydroxytoluene), PG (propyl 3,4,5-trihydroxybenzoate), TOC ((2R)2,5,7,8-tetramethyl-2-[(4R,8R)-(4,8,12-trimethyltridecyl)]-6-

chromanol or $\alpha$-tocopherol), ETX (6-ethoxy-2,2,4-trimethyl-1,2dihydroquinoline or ethoxyquin) and TBHQ (tert-butylhydroquinone), with a purity higher than $98 \%$, were purchased from Sigma S.A. (St. Louis, MO, USA). All other chemicals and solvents were of analytical grade and purchased from common sources. Water was treated in a Milli-Q water purification system (Millipore, model A10, Billerica, MA, USA).

\subsection{Preparation of the extracts}

\subsubsection{Plant material}

Unmarketable ripe red tomato (Lycopersicon esculentum Mill.) surpluses from a farmers' variety (locally known as "tomate redondo") were directly obtained from a local producer in Miranda do Douro, North-eastern Portugal. Pericarps without seeds, corresponding to most common tomato wastes, were lyophilized (Free Zone 4.5, Labconco, Kansas City, MO, USA), reduced to a fine dried powder (20 mesh) and kept at $-20^{\circ} \mathrm{C}$ until analysis.

\subsubsection{Microwave-assisted extraction}

The MAE process was performed in a microwave apparatus using closed vials of $20 \mathrm{~mL}$ (final volume). The powdered dried samples were extracted at different time $(t)$, temperature $(T)$, ethanol concentration $(E t)$ and solid/liquid ratio $(S / L)$ ranging as defined by the RSM experimental design presented in Table A1. During extraction, samples were stirred at $600 \mathrm{rpm}$ and irradiated at $200 \mathrm{~W}$. After that, the reaction mixture in the closed vial was quickly cooled in the processing chamber and then centrifuged at $6000 \mathrm{rpm}$ for $10 \mathrm{~min}$. The supernatant was carefully collected, evaporated under reduced pressure to remove the solvent and finally re-suspended in distilled water for further analysis. A full diagram of the process performed is presented in Fig. A1.

\subsection{Evaluation of the extraction yield}

The extracted residue (\%) was evaluated gravimetrically in crucibles by partially evaporating the water at $60{ }^{\circ} \mathrm{C}$ followed by a treatment at $105^{\circ} \mathrm{C}$ during $24 \mathrm{~h}$.

\subsection{Evaluation of compositional parameters}

Total sugars (TS) were evaluated by the phenol-sulphuric acid method using glucose as standard (Dubois, Gilles, Hamilton, Rebers, \& Smith, 1956) and expressed in $\mathrm{mg}$ per $\mathrm{g}$ of extract ( $\mathrm{mg} / \mathrm{g} \mathrm{E}$ ).

Reducing sugars (RS) were evaluated by the 3,5-dinitrosalicylic acid (DNS) reaction using glucose as standard (Bernfeld P, 1951) and expressed in mg per $\mathrm{g}$ of extract $(\mathrm{mg} / \mathrm{g} \mathrm{E}$ ).

The total protein content (PROT) was calculated by multiplying the total nitrogen content by the conversion factor of 6.25 (Havilah, E.J., Wallis, D.M., Morris, R., Woolnough, J.A., 1977) and expressed in mg per $g$ of extract ( $\mathrm{mg} / \mathrm{g} \mathrm{E}$ ).

The total phenolic content (TPC) was determined by the FolinCiocalteu method with some modifications (Pereira, Barros, Carvalho, \& Ferreira, 2011) using gallic acid as standard and expressed as mg of gallic acid equivalents (GAE) per g of extract (mg GAE/g E).

The total flavonoid content (TFC) was determined by the colorimetric method as described by the authors (Barros, Carvalho, Morais, \& Ferreira, 2010) using catechin as standard, and expressed as mg of catechin equivalents (CE) per g of extract ( $\mathrm{mg} \mathrm{CE} / \mathrm{g} \mathrm{E}$ ). 


\subsection{Evaluation of the antioxidant activity}

\subsubsection{ABTS assay}

The ABTS ${ }^{+}{ }^{+}$solution $(250 \mu \mathrm{L})$ prepared according to other authors (Prieto, Curran, Gowen, \& Vázquez, 2015) was mixed with the extracts $(50 \mu \mathrm{L})$ in a 96-well microplate (flat bottom). The microplate reader was programmed to read the absorbance at $414 \mathrm{~nm}$ to follow the reduction of ABTS ${ }^{+}$( $15 \mathrm{nM}$ ) at $30^{\circ} \mathrm{C}$ by monitoring the decrease in absorbance until the reaction reached a steady state (Serpen, Capuano, Fogliano, \& Gökmen, 2007).

The asymptotic variation of the ABTS ${ }^{+}$scavenging activity in function of an antioxidant compound suggests that some radical-generating properties of the system can be saturated (Gieseg \& Esterbauer, 1994). In general, these patterns can be adjusted by a group of mathematical expressions (mechanistic or not) that translates the pattern of the response into parameters that allow to deduce the meaning and/or quantify the effect of the dependent variable in a simple and global mode. The applicability of different mathematical expressions to quantify the antioxidant response have been discussed (Prieto, Vázquez, \& Murado, 2014). In this sense, the Weibull cumulative distribution function was selected (Weibull \& Sweden, 1951). Thus, the variation of the ABTS•+ response $(R)$ in function of increasing concentrations of an antioxidant $(A)$ was described using the Weibull model rearranged for our own purposes according to Eq. (1).

$R(A)=K\left\{1-\exp \left[-\ln (2)^{1-a}\left(\frac{2 V_{m}}{K a} A\right)^{a}\right]\right\}$

where the parameter $K$ is the concentration of the ABTS ${ }^{+}(15 \mathrm{nM})$ and is the starting point of the response. The parameter $V_{m}$ corresponds to the average amount of scavenged molecules per $g$ of extracted material (nM of ABTS/g E). The parameter $a$ is a shape parameter related to the slope that can produce potential profiles $(a<1)$, first order kinetic ones $(a=1)$ and a variety of sigmoid profiles $(a>1)$. For the calculation of the $I C_{50}$ the following relation was used:

$I C_{50}=\frac{K a \ln 2}{2 V_{\mathrm{m}}}$

\subsubsection{Oxidative haemolysis inhibition assay (OxHLIA)}

Erythrocytes were obtained from different adult sheep, washed at least three times with PBS and re-suspended in PBS at $2.8 \%(\mathrm{v} / \mathrm{v})$ (Takebayashi et al., 2007). The erythrocyte suspensions (50 $\mu \mathrm{L}$ ), in the absence or presence of an antioxidant sample $(100 \mu \mathrm{L})$ in PBS, were added to a 96-well flat bottom microplate. Complete haemolysis was obtained by adding water to the erythrocyte suspension without sample. The plate was pre-incubated with a lid at $37^{\circ} \mathrm{C}$, then AAPH $(50 \mu \mathrm{L}$, $160 \mathrm{mM}$ in PBS) was added to initiate the assay and incubated at $37{ }^{\circ} \mathrm{C}$ in with shaking. The optical density at $660 \mathrm{~nm}$ was measured every $10 \mathrm{~min}$ (Takebayashi, Iwahashi, Ishimi, \& Tai, 2012). The percentage of survival erythrocyte population $(P)$ was calculated using Eq. (3):

$P=\left(\frac{n_{t}-n_{\max }}{n_{0}-n_{\max }}\right) \times 100$

where $n$ is the optical density measure at the start of the reaction (0) or at any $t(\mathrm{~min})$ and $n_{\max }$ is the maximum optical density of the complete haemolysis. Then, the time to reach $50 \%$ of the survival population $\left(I C_{50}\right)$ was obtained graphically for an increasing concentration of an antioxidant. Afterwards, the $\tau$ values for each dose tested were analyzed linearly as follows:

$I C_{50}(D)=b+m D$

where $I C_{50}$ is the dose needed to reach $50 \%$ of the lysed erythrocyte population, $b$ is the intercept ( $\mathrm{min}$ ) and $m$ is the slope of the process (min/g E).

\subsubsection{Evaluated commercial food additives}

The antioxidant activity of the extracts was compared to that of different commercial antioxidants, which are listed below:

(a) BHA (E320): a synthetic antioxidant mainly used as preservative in lipophilic and hydrophilic environments.

(b) BHT (E321): a synthetic lipophilic antioxidant compound used as food additive.

(c) PG (E310): an antioxidant commonly added in lipophilic foods to prevent oxidation.

(d) TOC (E306): a lipophilic compound useful for its antioxidant properties.

(e) ETX (E324): a synthetic lipophilic preservative commonly used in animal feeds.

(f) TBHQ (E319): a synthetic highly effective antioxidant in foods.

(g) Trolox: a water-soluble antioxidant compound used in biological or biochemical applications for oxidation inhibition purposes.

\subsection{Response surface methodology}

\subsubsection{Experimental design}

A five-level CCCD coupled with RSM was applied to optimize the MAE conditions for production of nutritionally valuable ingredients with antioxidant properties from tomato wastes. It was intended to produce a final product with potential as a food additive or ingredient for fortification and functionalisation purposes. For this, the four independent variables of extraction time ( $\mathrm{min}, x_{1}$ ), temperature $\left({ }^{\circ} \mathrm{C}, x_{2}\right)$, ethanol concentration $\left(\%, x_{3}\right)$ and solid/liquid ratio $\left(\mathrm{g} / \mathrm{L}, x_{4}\right)$ were selected based on a previous study (Pinela, Prieto, Barreiro, et al., 2016a). The same study also found that the microwave power do not influence the MAE process. The combined effects of these four variables on the evaluated responses were evaluated in a CCCD as proposed by Box and Hunter (Box \& Hunter, 1957). The optimization study was solved using 25 independent combinations and 7 replicates at the centre of the experimental domain, which, in other cases, could imply 625 possible combinations. In this design, the experimental points are generated on a sphere around the centre point (five levels of each factor), which is a supposed to be an optimum position for the response and is repeated to maximize the prediction (Box, Hunter, \& Hunter, 2005). A detail description of the mathematical expressions to calculate the design distribution and to decode and code the ranges of the variables tested can be found in Table A1 of the Supplemental material.

\subsubsection{Mathematical modelling}

The response surface models were fitted by means of least-squares calculation using the following second-order polynomial equation:

$$
Y=b_{0}+\sum_{i=1}^{n} b_{i} X_{i}+\sum_{\substack{i=1 \\ j>i}}^{n-1} \sum_{j=2}^{n} b_{i j} X_{i} X_{j}+\sum_{i=1}^{n} b_{i i} X_{i}^{2}
$$

where $Y$ is the dependent variable (response variable) to be modelled, $X_{i}$ and $X_{j}$ define the independent variables, $b_{0}$ is the constant coefficient, $b_{i}$ is the coefficient of linear effect, $b_{i j}$ is the coefficient of interaction effect, $b_{i i}$ the coefficients of quadratic effect and $n$ is the number of variables. Although the model parameters obtained are empirical and cannot be associated with a mechanistic meaning, they are useful to predict the results of untested operation conditions (Pinela et al., 2016a). The sign of the effect marks the response performance. In this way, when a factor has a positive effect, the response is higher at the high level and when a factor has a negative effect, the response is lower at the high level. The 
higher the absolute value of a coefficient, the more important the weight of the corresponding variable (Heleno et al., 2016).

2.6.3. Simplex procedure for optimize the variables to a maximum response

For optimization of the MAE conditions, the parametric model responses produced were integrated into a simplex tool to solve non-linear problems (Heleno et al., 2016; Pinela et al., 2016a) and find the variable values that will maximize the extraction of nutrients and phytochemicals of interest. Limitations were made to the variable coded values to avoid unnatural conditions (i.e., lower times than 0 or higher values than $100 \%$ of the solvent).

\subsection{Numerical methods and statistical analysis}

All fitting procedures, coefficient estimates and statistical calculations were performed using a Microsoft Excel spreadsheet and graphical illustrations presented were developed in the software DeltaGraph V6. Fitting and statistical analysis of the experimental results according to the proposed equations were carried out in four phases:

Coefficients determination: Parametric estimates were obtained by minimization of the sum of quadratic differences between observed and model-predicted values, using the nonlinear least-square (quasiNewton) method provided by the macro Solver in Microsoft Excel 2003 (Kemmer \& Keller, 2010), which allows a quick testing of a hypotheses and its consequences (Murado \& Prieto, 2013).

Coefficients significance: The determination of the parametric confidence intervals done using the 'SolverAid' (Prikler, 2009). The model was simplified by dropping the terms which were not statistically significant at $\alpha=0.05$.

Model consistency: The Fisher $F$ test $(\alpha=0.05)$ was used to determine whether the constructed models were adequate to describe the observed data (Shi \& Tsai, 2002).

Other statistical assessment criteria: To re-check the uniformity of the model the following criteria were applied: a) the 'SolverStat' macro (Comuzzi, Polese, Melchior, Portanova, \& Tolazzi, 2003), which was used for the assessment of parameter and model prediction uncertainties; b) $R^{2}$ that is interpreted as the proportion of the variability of the dependent variable explained by the model; c) adjusted coefficient of determination $\left(\mathrm{R}^{2}{ }_{\mathrm{adj}}\right)$, which is a correction to $\mathrm{R}^{2}$ taking into account the number of variables used in the model; $d$ ) bias and accuracy factors of all equations were calculated to evaluate the quality of fittings to experimental data, such as the Mean Squared Error (MSE), the Root Mean Square of the Errors (RMSE) and the Mean Absolute Percentage Error (MAPE); e) the Durbin-Watson coefficient (DW) to check if the residuals of the model are not auto-correlated; and f) the Analysis of Variance table (ANOVA) to evaluate the explanatory power of the variables.

\section{Results and discussion}

\subsection{Preliminary experiments}

A preliminary study was carried out to centre the experimental domain of the variables and select the relevant ones before RSM application. The parametric results obtained from the preliminary analysis of the relevant system variables are presented in Table A2. The extraction yield, TPC and TFC were evaluated as responses. Only linear relations were found and the confidence interval of the slope was used to test the statically significance (s) or non-significance (ns) of the independent variable on the evaluated response. Other statistical information such as the correlation coefficient and $\mathrm{F}$ test are also displayed. Et and $S / L$ had significant effects on the three measured responses. The $T$ induced significant effects on TPC and TFC. The $t$ was only significant for TPC. The absorption level, an internal factor of the instrument software, did not induced significant changes on the evaluated responses. These results are in agreement with those reported in a study to optimize the extraction of hydrophilic and lipophilic antioxidants from a surplus production of tomato (Pinela et al., 2016a).

\subsection{RSM analysis}

\subsubsection{Determination of the parameters that will be used as responses for the} analysis of the antioxidant behaviour in the RSM

Fig. A2 illustrates the antioxidant responses of the ABTS•+ assay for the different extracts obtained under the RSM experimental design presented in Table A1. Each graph illustrates the dose responses of the 25 independent variable combinations, in which dots represents the remaining $\mathrm{nM}$ of ABTS radicals in function of the used concentration (which were standardized into $0-1$ format to be able to display all of them together) and lines represent the fitted response to the mathematical model of Eq. (1). The obtained parametric fitting values are shown in Table A3. The parameter $K$ is the initial concentration of ABTS ${ }^{+}(15 \mathrm{nM})$ used in the antioxidant reaction, the parameter $V_{m}$ corresponds to the amount of scavenged nM ABTS/g E which ranged from 1.71 to 3.11 , and the parameter $I C_{50}$ indicates the concentration needed to reach $50 \%$ of the maximum protective effect obtaining the lowest value (corresponding to the highest activity) at run no. 23 ( $1.70 \mathrm{~g} \mathrm{E})$. All coefficients showed effects with significant parametric intervals at the $95 \%$ confidence level $(\alpha=0.05)$

The OxHLIA assay is based on the inhibition of free radical-induced membrane damage in sheep erythrocytes by antioxidants. The erythrocytes are subjected to haemolytic activity by the action of hydrophilic and lipophilic radicals in an aqueous system (Prieto \& Vázquez, 2014). The hydrophilic radicals result from the thermal decomposition of AAPH, which attacks the biomembranes of erythrocytes and eventually cause haemolysis. Because of this attack, lipophilic radicals are generated through a lipid peroxidation phenomenon. The antioxidants can capture the hydrophilic and/or lipophilic radicals and, consequently, retarded the haemolytic time. Additionally, these radicals and substrate targets are biologically relevant compared to other in vitro assays; for this reason, this bioassay is considered as being halfway between in vitro and in vivo. The antioxidant responses of the OxHLIA assay are illustrated in Fig. A3 for the extracts obtained under the RSM experimental design (Table A1). On the left-hand side, each graph illustrates the concentration-time responses of seven serial dilutions and the control of the 25 independent variable combinations. For each graph on the right-hand side, dots represent the extension of half-life spam of the erythrocyte population values in a concentration-response format obtained from the concentration-time responses presented in the left-hand side, and lines represent the fitted responses to the mathematical model of Eq. (4). The obtained parametric fitting values are shown in Table A3. The parameter $b$ is the intercept ( $\mathrm{min}$ ) which corresponds to the haemolytic time of the reaction without antioxidant (control) and $m$ is the slope of the process ( $\mathrm{min} / \mathrm{g} \mathrm{E}$ ) that measures the sample capacity to extend the half-life of the erythrocyte population. Therefore, the higher the $m$ value, the higher the antioxidant capacity of the extract, i.e., the higher free radical-induced membrane damage inhibition capacity of the extracts. The highest response $(16.8 \mathrm{~min} / \mathrm{g} \mathrm{E})$ was achieved with the run $n^{\circ} 16$.

\subsubsection{Mathematical models developed from the CCCD with four variables}

The results obtained according to the statistical CCCD are shown in Table 1 for each of the computed responses. After fitting Eq. (5) to the response results of Table 1 using a non-linear least-squares procedure, the estimated parametric values, parametric intervals and numerical statistical criteria were obtained and presented in Table 2. Those coefficients, which showed effects with coefficient interval values $(\alpha=0.05)$ higher than the parameter value 
Table 1

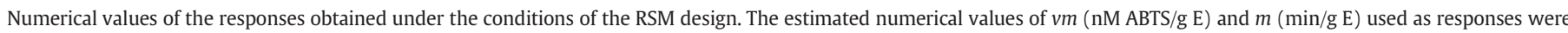
achieved using the Eq. (1) and Eq. (4), respectively.

\begin{tabular}{|c|c|c|c|c|c|c|c|c|c|c|c|c|}
\hline \multirow[t]{2}{*}{ Run } & \multicolumn{4}{|c|}{ Experimental domain } & \multirow{2}{*}{$\frac{\text { Residue }}{\text { Yield }}$} & \multicolumn{5}{|c|}{ Compositional parameters } & \multicolumn{2}{|c|}{ Antioxidant activity } \\
\hline & $\begin{array}{l}\mathrm{X}_{1}: \mathrm{t} \\
\min \end{array}$ & $\begin{array}{l}\mathrm{X}_{2}: \mathrm{T} \\
{ }^{\circ} \mathrm{C}\end{array}$ & $\begin{array}{l}\mathrm{X}_{3}: \mathrm{Et} \\
\%\end{array}$ & $\begin{array}{l}\mathrm{X}_{4}: \mathrm{S} / \mathrm{L} \\
\mathrm{g} / \mathrm{L}\end{array}$ & & $\begin{array}{l}\mathrm{TS} \\
\mathrm{mg} / \mathrm{g} \mathrm{E}\end{array}$ & $\begin{array}{l}\mathrm{RS} \\
\mathrm{mg} / \mathrm{g} \mathrm{E}\end{array}$ & $\begin{array}{l}\text { PROT } \\
\mathrm{mg} / \mathrm{g} \mathrm{E}\end{array}$ & $\begin{array}{l}\text { TPC } \\
\mathrm{mg} \mathrm{GAE} / \mathrm{g} \mathrm{E}\end{array}$ & $\begin{array}{l}\mathrm{TFC} \\
\mathrm{mg} \mathrm{CE} / \mathrm{g} \mathrm{E}\end{array}$ & $\begin{array}{l}\text { ABTS } \\
\text { nM ABTS/g E }\end{array}$ & $\begin{array}{l}\text { OxHLIA } \\
\mathrm{min} / \mathrm{g} \mathrm{E}\end{array}$ \\
\hline 1 & $-1(5)$ & $-1(90)$ & $-1(25)$ & $-1(15)$ & 71.08 & 646.0 & 324.7 & 35.26 & 6.81 & 0.51 & 2.41 & 2.28 \\
\hline 2 & $1(15)$ & $-1(90)$ & $-1(25)$ & $-1(15)$ & 71.16 & 577.3 & 399.1 & 47.28 & 5.37 & 0.38 & 2.75 & 2.70 \\
\hline 3 & $-1(5)$ & $1(150)$ & $-1(25)$ & $-1(15)$ & 68.90 & 569.3 & 405.6 & 46.20 & 8.98 & 0.66 & 2.94 & 3.43 \\
\hline 4 & $1(15)$ & $1(150)$ & $-1(25)$ & $-1(15)$ & 69.42 & 596.4 & 444.4 & 58.25 & 14.14 & 0.84 & 2.67 & 8.03 \\
\hline 5 & $-1(5)$ & $-1(90)$ & $1(75)$ & $-1(15)$ & 73.51 & 715.2 & 543.5 & 25.91 & 14.23 & 0.99 & 1.71 & 6.59 \\
\hline 6 & $1(15)$ & $-1(90)$ & $1(75)$ & $-1(15)$ & 69.86 & 634.6 & 490.1 & 36.38 & 7.64 & 0.69 & 2.09 & 10.26 \\
\hline 7 & $-1(5)^{\prime}$ & $1(150)$ & $1(75)$ & $-1(15)$ & 67.68 & 591.2 & 442.8 & 35.66 & 21.69 & 1.04 & 2.16 & 10.48 \\
\hline 8 & $1(15)$ & $1(150)$ & $1(75)$ & $-1(15)$ & 67.20 & 602.8 & 397.8 & 46.73 & 26.09 & 1.26 & 2.59 & 15.72 \\
\hline 9 & $-1(5)^{\prime}$ & $-1(90)$ & $-1(25)$ & $1(35)$ & 67.01 & 726.1 & 392.1 & 51.71 & 6.72 & 0.27 & 2.28 & 2.43 \\
\hline 10 & $1(15)^{\circ}$ & $-1(90)$ & $-1(25)$ & $1(35)$ & 67.24 & 634.4 & 442.1 & 63.20 & 5.37 & 0.16 & 2.63 & 2.98 \\
\hline 11 & $-1(5)^{\prime}$ & $1(150)$ & $-1(25)$ & $1(35)$ & 70.01 & 582.6 & 443.5 & 66.24 & 9.67 & 0.77 & 2.93 & 3.82 \\
\hline 12 & $1(15)$ & $1(150)$ & $-1(25)$ & $1(35)$ & 70.12 & 613.1 & 486.1 & 78.15 & 13.51 & 1.00 & 2.88 & 9.04 \\
\hline 13 & $-1(5)$ & $-1(90)$ & $1(75)$ & $1(35)$ & 60.62 & 673.0 & 523.8 & 38.07 & 7.37 & 0.57 & 2.07 & 6.16 \\
\hline 14 & $1(15)$ & $-1(90)$ & $1(75)$ & $1(35)$ & 60.72 & 625.1 & 482.7 & 48.35 & 6.20 & 0.46 & 2.43 & 9.92 \\
\hline 15 & $-1(5)$ & $1(150)$ & $1(75)$ & $1(35)$ & 64.58 & 532.0 & 427.8 & 51.82 & 21.72 & 1.28 & 2.43 & 9.58 \\
\hline 16 & $1(15)$ & $1(150)$ & $1(75)$ & $1(35)$ & 64.95 & 533.9 & 380.7 & 63.06 & 27.70 & 1.72 & 2.61 & 14.92 \\
\hline 17 & $-2(0)$ & 0 (120) & $0(50)$ & $0(25)$ & 68.96 & 617.7 & 471.2 & 53.91 & 6.79 & 0.43 & 2.21 & 4.49 \\
\hline 18 & $2(20)$ & $0(120)$ & $0(50)$ & $0(25)$ & 68.52 & 603.3 & 467.4 & 76.64 & 6.50 & 0.43 & 2.55 & 12.87 \\
\hline 19 & $0(10)$ & $-2(60)$ & $0(50)$ & $0(25)$ & 71.53 & 624.4 & 428.4 & 38.31 & 8.54 & 0.85 & 1.88 & 3.20 \\
\hline 20 & $0(10)$ & $2(180)$ & $0(50)$ & $0(25)$ & 72.51 & 482.8 & 378.9 & 64.15 & 38.63 & 2.86 & 2.58 & 5.45 \\
\hline 21 & $0(10)$ & 0 (120) & $-2(0)$ & $0(25)$ & 64.90 & 629.5 & 432.9 & 36.81 & 5.05 & 0.23 & 2.83 & 2.51 \\
\hline 22 & $0(10)$ & $0(120)$ & $2(100)$ & $0(25)$ & 52.58 & 650.2 & 513.6 & 14.71 & 15.64 & 0.71 & 2.15 & 15.42 \\
\hline 23 & $0(10)$ & 0 (120) & $0(50)$ & $-2(5)$ & 71.60 & 659.9 & 406.8 & 41.15 & 4.98 & 0.56 & 2.59 & 8.09 \\
\hline 24 & $0(10)$ & 0 (120) & $0(50)$ & $2(45)$ & 64.83 & 633.4 & 443.5 & 72.98 & 5.70 & 0.46 & 3.11 & 8.81 \\
\hline 25 & $0(10)$ & 0 (120) & $0(50)$ & $0(25)$ & 68.89 & 623.0 & 470.2 & 65.46 & 5.61 & 0.46 & 2.85 & 8.29 \\
\hline 26 & $0(10)$ & $0(120)$ & $0(50)$ & $0(25)$ & 68.48 & 656.8 & 475.0 & 65.06 & 5.68 & 0.46 & 2.41 & 8.14 \\
\hline 27 & $0(10)$ & $0(120)$ & $0(50)$ & $0(25)$ & 68.50 & 646.1 & 470.0 & 65.08 & 5.70 & 0.45 & 2.75 & 8.15 \\
\hline 28 & $0(10)$ & $0(120)$ & $0(50)$ & $0(25)$ & 68.47 & 640.5 & 470.9 & 65.06 & 5.72 & 0.45 & 2.94 & 8.24 \\
\hline 29 & $0(10)$ & 0 (120) & $0(50)$ & $0(25)$ & 68.67 & 651.9 & 471.2 & 65.24 & 6.27 & 0.47 & 2.67 & 8.10 \\
\hline 30 & $0(10)$ & $0(120)$ & $0(50)$ & $0(25)$ & 68.43 & 637.0 & 471.9 & 65.01 & 6.02 & 0.44 & 1.71 & 8.14 \\
\hline 31 & $0(10)$ & $0(120)$ & $0(50)$ & $0(25)$ & 68.85 & 643.8 & 470.1 & 65.41 & 6.34 & 0.43 & 2.09 & 8.11 \\
\hline 32 & $0(10)$ & 0 (120) & $0(50)$ & $0(25)$ & 68.70 & 652.7 & 471.5 & 65.27 & 6.31 & 0.44 & 2.16 & 8.17 \\
\hline
\end{tabular}

Table 2

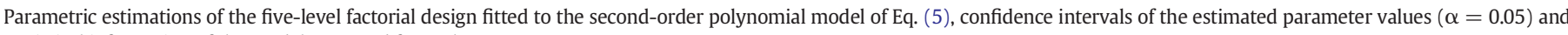
statistical information of the model proposed for each response.

\begin{tabular}{|c|c|c|c|c|c|c|c|c|c|}
\hline & & \multirow{2}{*}{$\frac{\text { Residue }}{\text { Yield }}$} & \multicolumn{5}{|c|}{ Compositional parameters } & \multicolumn{2}{|c|}{ Antioxidant activity } \\
\hline & & & TS & RS & PROT & TPC & TFC & ABTS & OxHLIA \\
\hline \multicolumn{10}{|c|}{ Fitting coefficients obtained from Eq. (5) } \\
\hline Intercept & $\mathrm{b}_{0}$ & $68.80 \pm 0.59$ & $644.57 \pm 6.33$ & $470.27 \pm 3.14$ & $65.17 \pm 1.95$ & $6.32 \pm 1.01$ & $0.45 \pm 0.06$ & $2.85 \pm 0.06$ & $8.41 \pm 0.41$ \\
\hline \multirow[t]{4}{*}{ Linear effect } & $b_{1}$ & $-0.15 \pm 0.04$ & $-10.26 \pm 4.83$ & ns & $5.67 \pm 1.13$ & $0.34 \pm 0.08$ & $0.02 \pm 0.01$ & $0.10 \pm 0.04$ & $1.90 \pm 0.37$ \\
\hline & $b_{2}$ & ns & $-37.23 \pm 4.83$ & $-11.18 \pm 2.40$ & $6.32 \pm 1.13$ & $6.00 \pm 0.77$ & $0.36 \pm 0.05$ & $0.18 \pm 0.04$ & $1.51 \pm 0.37$ \\
\hline & $b_{3}$ & $-2.10 \pm 0.45$ & ns & $21.39 \pm 2.40$ & $-6.02 \pm 1.13$ & $3.47 \pm 0.77$ & $0.18 \pm 0.05$ & $-0.20 \pm 0.04$ & $3.11 \pm 0.37$ \\
\hline & $\mathrm{b}_{4}$ & $-1.96 \pm 0.45$ & ns & $8.51 \pm 2.40$ & $8.03 \pm 1.13$ & ns & ns & $0.08 \pm 0.04$ & ns \\
\hline \multirow[t]{4}{*}{ Quadratic effect } & $b_{11}$ & ns & $-7.89 \pm 4.33$ & ns & ns & ns & ns & $-0.12 \pm 0.03$ & ns \\
\hline & $b_{22}$ & $0.97 \pm 0.40$ & $-22.12 \pm 4.33$ & $-17.44 \pm 2.15$ & $-3.54 \pm 1.02$ & $4.58 \pm 0.69$ & $0.35 \pm 0.05$ & $-0.16 \pm 0.03$ & $-1.02 \pm 0.33$ \\
\hline & $b_{33}$ & $-2.35 \pm 0.40$ & ns & ns & $-9.91 \pm 1.02$ & $1.27 \pm 0.69$ & ns & $-0.09 \pm 0.03$ & ns \\
\hline & $b_{44}$ & ns & ns & $-12.07 \pm 2.15$ & $-2.08 \pm 1.02$ & ns & ns & ns & ns \\
\hline \multirow[t]{6}{*}{ Interactive effect } & $b_{12}$ & ns & $22.48 \pm 5.92$ & ns & ns & $1.87 \pm 0.95$ & $0.11 \pm 0.07$ & $-0.07 \pm 0.05$ & $0.75 \pm 0.46$ \\
\hline & $b_{13}$ & ns & ns & $-24.52 \pm 2.93$ & ns & ns & ns & $0.06 \pm 0.05$ & ns \\
\hline & $b_{14}$ & ns & ns & ns & ns & ns & ns & ns & ns \\
\hline & $b_{23}$ & ns & $-10.36 \pm 5.92$ & $-38.29 \pm 2.93$ & ns & $2.48 \pm 0.95$ & ns & ns & ns \\
\hline & $b_{24}$ & $1.65 \pm 0.55$ & $-11.49 \pm 5.92$ & ns & ns & ns & $0.13 \pm 0.07$ & ns & ns \\
\hline & $b_{34}$ & $-1.32 \pm 0.55$ & $-21.69 \pm 5.92$ & $-15.59 \pm 2.93$ & ns & ns & ns & $0.06 \pm 0.05$ & ns \\
\hline \multicolumn{10}{|c|}{ Statistical information of the fitting analysis } \\
\hline Observations & & 32 & 32 & 32 & 32 & 32 & 32 & 32 & 32 \\
\hline $\mathrm{R}^{2}$ & & 0.9552 & 0.9627 & 0.9723 & 0.9794 & 0.9690 & 0.9573 & 0.9565 & 0.9675 \\
\hline $\mathrm{R}^{2} \mathrm{adj}$ & & 0.9182 & 0.9319 & 0.9460 & 0.9590 & 0.9435 & 0.9222 & 0.9206 & 0.9407 \\
\hline MSE & & 29.5 & 4358.6 & 3886.4 & 434.3 & 120.3 & 0.5 & 0.2 & 25.6 \\
\hline RMSE & & 5.43 & 66.02 & 62.34 & 20.84 & 10.97 & 0.70 & 0.47 & 5.06 \\
\hline MAPE & & 0.87 & 1.20 & 0.71 & 0.74 & 11.33 & 12.50 & 2.01 & 8.68 \\
\hline DW & & 1.65 & 2.61 & 1.88 & 2.05 & 1.77 & 2.31 & 2.38 & 2.53 \\
\hline
\end{tabular}

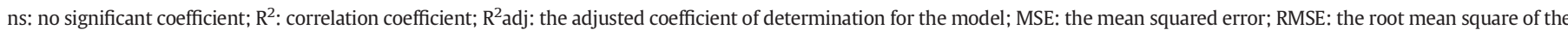
errors; MAPE: the mean absolute percentage error; and DW: the Durbin-Watson statistic. 
were consider as non-significant (ns) and were not used in model development.

Therefore, mathematical models were built, obtaining the following second-order polynomial equations according to Eq. (5) for each of the responses assessed:

For the extraction yield:

\begin{tabular}{lll}
\hline $\begin{array}{l}\text { for the } \\
\text { residue: }\end{array}$ & $Y_{\text {Yield }}=68.8-0.15 x_{1}-2.1 x_{3}-2.0 x_{4}+1.0 x_{2}^{2}-2.4 x_{3}^{2}+1.6 x_{2} x_{4}-1.3 x_{3} x_{4}$ & $(6)$ \\
\hline \multicolumn{2}{c}{ For each compositional parameter: } & \\
& & \\
\hline for the & & \\
TS: & $Y_{\mathrm{TS}}=644-10 x_{1}-37 x_{2}-8 x_{1}^{2}-22 x_{2}^{2}-10 x_{2} x_{3}-11 x_{2} x_{4}-21 x_{3} x_{4}$ & $(7)$ \\
for the & $Y_{\mathrm{RS}}=470-11 x_{2}-21 x_{3}-8.5 x_{4}-17.5 x_{2}^{2}-12 x_{4}^{2}-24.5 x_{1} x_{3}$ & $(8)$ \\
RS: & $-38 x_{2} x_{3}-15.5 x_{3} x_{4}$ \\
for the & $Y_{\mathrm{PROT}}=65.1+5.6 x_{1}+6.3 x_{2}-6.1 x_{3}-8.0 x_{4}-3.5 x_{2}^{2}-9.9 x_{3}^{2}-2.1 x_{4}^{2}$ & $(9)$ \\
PROT: & $Y_{\mathrm{TPC}}=6.3+0.3 x_{1}+6 x_{2}+3.5 x_{3}+4.5 x_{2}^{2}+1.2 x_{3}^{2}+1.9 x_{1} x_{2}+2.5 x_{2} x_{3}$ & $(10)$ \\
for the & & \\
TPC: & & \\
for the & $Y_{\mathrm{TFC}}=0.45+0.02 x_{1}+0.36 x_{2}+0.18 x_{3}+0.35 x_{2}^{2}+0.11 x_{1} x_{2}+0.13 x_{2} x_{4}$ & \\
TFC: & & \\
\hline
\end{tabular}

For each antioxidant activity:

\begin{tabular}{lcc}
\hline & $Y_{\mathrm{ABTS}}=2.85+0.1 x_{1}+0.18 x_{2}-0.2 x_{3}+0.08 x_{4}-0.12 x_{1}^{2}-0.16 x_{2}^{2}$ \\
for the ABTS: & $-0.1 x_{3}^{2}-0.07 x_{1} x_{2}+0.06 x_{1} x_{3}+0.06 x_{3} x_{4}$ & $(12)$ \\
for the OxHLIA: & $Y_{\text {OxHLIA }}=8.4+1.9 x_{1}+1.5 x_{2}+3.1 x_{3}-1.1 x_{2}^{2}+0.75 x_{1} x_{2}$
\end{tabular}

where $x_{1}$ (extraction time), $x_{2}$ (temperature), $x_{3}$ (ethanol concentration), $x_{4}$ (solid/liquid ratio), $Y$ is the response, sub-indices indicate the analytical criteria used as responses for RSM. The Eqs. (6) to (13) translate the response patterns for each response showing sceneries with complex diversity. Linear, quadratic and interactive effects were found playing an important and significant role in all responses tested.

\subsubsection{Detailed analysis of the obtained response patterns}

The best way to visualize the effect of the independent variables on the studied responses (dependent variables) is to draw 3D response surface graphs of the model, which were done by varying two variables within the experimental range and holding the other ones constant at the centre of their experimental domain $\left(t=10 \mathrm{~min}, T=120^{\circ} \mathrm{C}\right.$, $E t=50 \%$ and $S / L=25 \mathrm{~g} / \mathrm{L}$ ). The analysis of the model is presented below.

3.2.3.1. Extraction yield. The results of the extraction yield are presented in Table 1. The amount of extracted residue ranged from 52.58 to $73.51 \%$ with the experimental runs no. 22 and 5, respectively. Fig. 3 shows that the increase in $T$ and $S / L$ increased the extraction yield. The interaction between these two variables (Table 2) is represented in the 3D graph of Fig. 2, where it can be seen that despite the higher extraction yield occurred at higher $T$ and $S / L$, low ranges of these variables also induced a positive effect in the response. In turn, the increase in Et up to $24.7 \%$ increased the quantity of extracted residue, but the response gradually decreased at higher Et (Fig. 3). The negative interaction between this variable and $S / L$ is shown in Fig. 3; the higher responses were obtained at high $S / L$ and low $E t$ and at low $S / L$ and high $E t$. The optimal extraction conditions ( $t=2 \mathrm{~min}, T=180{ }^{\circ} \mathrm{C}, E t=24.7 \%$ and $S / L=45 \mathrm{~g} / \mathrm{L}$ ) originated a extraction yield of $78 \%$ (Table 3 ).

3.2.3.2. Compositional parameters. The amounts of TS, RS, PROT, TPC and TFC in the different extracts produced under the RSM experimental design are presented in Table 1 . The TS content ranged from 482.8 to $726.1 \mathrm{mg} / \mathrm{g}$ extract, while the quantity of reducing sugars ranged from 324.7 to $543.5 \mathrm{mg} / \mathrm{g}$ E. Curiously, these responses were affected in a contrary way as can be seen in the $2 \mathrm{D}$ individual responses of Fig. 3. Longer $t$ and higher $T$ decreased the TS content in a non-linear way (Table 2), but a positive interaction occurred between these variables. This interaction
Table 3

Optimal processing conditions in natural values that lead to optimal response values.

\begin{tabular}{|c|c|c|c|c|c|c|}
\hline & \multicolumn{4}{|c|}{ Optimal processing conditions } & \multicolumn{2}{|c|}{ Response optimum } \\
\hline & $\begin{array}{l}\mathrm{X}_{1}: \mathrm{t} \\
(\mathrm{min})\end{array}$ & $\begin{array}{l}\mathrm{X}_{2}: \mathrm{T} \\
\left({ }^{\circ} \mathrm{C}\right)\end{array}$ & $\begin{array}{l}\mathrm{X}_{3}: \text { Et } \\
(\%)\end{array}$ & $\begin{array}{l}\mathrm{X}_{4}: \mathrm{S} / \mathrm{L} \\
(\mathrm{g} / \mathrm{L})\end{array}$ & & \\
\hline \multicolumn{7}{|c|}{ For the extraction yield } \\
\hline Residue & 2.0 & 180.0 & 24.7 & 45.0 & $78.0 \pm 3.4$ & $\%$ \\
\hline \multicolumn{7}{|c|}{ For each compositional parameter } \\
\hline TS & 2.0 & 71.9 & 100.0 & 5.0 & $791.9 \pm 30.8$ & $\mathrm{mg} / \mathrm{g} \mathrm{E}$ \\
\hline RS & 20.0 & 176.3 & 0.0 & 41.5 & $619.5 \pm 50.2$ & $\mathrm{mg} / \mathrm{g} \mathrm{E}$ \\
\hline PROT & 20.0 & 146.7 & 42.3 & 44.3 & $88.0 \pm 10.4$ & $\mathrm{mg} / \mathrm{g} \mathrm{E}$ \\
\hline TFC & 20.0 & 180.0 & 100.0 & 45.0 & $66.8 \pm 5.3$ & $\mathrm{mg} \mathrm{GAE} / \mathrm{g} \mathrm{E}$ \\
\hline TPC & 20.0 & 180.0 & 100.0 & 45.0 & $3.89 \pm 0.6$ & $\mathrm{mg} \mathrm{CE} / \mathrm{g} \mathrm{E}$ \\
\hline \multicolumn{7}{|c|}{ For each antioxidant activity } \\
\hline ABTS & 8.75 & 138.5 & 3.4 & 5.0 & $3.0 \pm 0.7$ & nM ABTS/g E \\
\hline OxHLIA & 20.0 & 164.2 & 100.0 & 45.0 & $20.6 \pm 3.7$ & $\mathrm{~min} / \mathrm{g} \mathrm{E}$ \\
\hline \multicolumn{7}{|c|}{$\begin{array}{l}\text { Intermediate conditions for extraction yield, compositional parameters and } \\
\text { antioxidant activity }\end{array}$} \\
\hline Residue & 2.0 & 180.0 & 24.7 & 45.0 & $78.0 \pm 3.4$ & $\%$ \\
\hline TS & 20.0 & 180.0 & 24.1 & 45.0 & $540.2 \pm 33.7$ & $\mathrm{mg} / \mathrm{g} \mathrm{E}$ \\
\hline RS & & & & & $487.8 \pm 44.4$ & $\mathrm{mg} / \mathrm{g} \mathrm{E}$ \\
\hline PROT & & & & & $78.2 \pm 18.1$ & $\mathrm{mg} / \mathrm{g} \mathrm{E}$ \\
\hline TFC & & & & & $37.4 \pm 16.3$ & $\mathrm{mg} \mathrm{GAE} / \mathrm{g} \mathrm{E}$ \\
\hline TPC & & & & & $3.3 \pm 1.5$ & $\mathrm{mg} \mathrm{CE} / \mathrm{g} \mathrm{E}$ \\
\hline ABTS & 20.0 & 143.3 & 100.0 & 45.0 & $2.4 \pm 0.6$ & nM ABTS/g E \\
\hline OxHLIA & & & & & $20.2 \pm 3.5$ & $\mathrm{~min} / \mathrm{g} \mathrm{E}$ \\
\hline \multicolumn{7}{|c|}{ Global processing conditions } \\
\hline Residue & 20.0 & 180.0 & 47.4 & 45.0 & $75.5 \pm 5.1$ & $\%$ \\
\hline TS & & & & & $480.3 \pm 41.8$ & $\mathrm{mg} / \mathrm{g} \mathrm{E}$ \\
\hline RS & & & & & $361.2 \pm 52.4$ & $\mathrm{mg} / \mathrm{g} \mathrm{E}$ \\
\hline PROT & & & & & $83.2 \pm 15.6$ & $\mathrm{mg} / \mathrm{g} \mathrm{E}$ \\
\hline TPC & & & & & $43.9 \pm 13.9$ & $\mathrm{mg} \mathrm{GAE} / \mathrm{g} \mathrm{E}$ \\
\hline TFC & & & & & $3.5 \pm 1.3$ & $\mathrm{mg} \mathrm{CE} / \mathrm{g} \mathrm{E}$ \\
\hline ABTS & & & & & $2.2 \pm 0.3$ & nM ABTS/g E \\
\hline OxHLIA & & & & & $13.8 \pm 2.4$ & $\mathrm{~min} / \mathrm{g} \mathrm{E}$ \\
\hline
\end{tabular}

is visually represented in the 3D graph of Fig. 1. In turn, the amount of RS was higher in the extracts obtained with a longer $t$ and a higher $T$ and $S / L$, but with a lower $E t$. In fact, while pure ethanol was appropriated to extract total sugars, water was suitable for the recovery of RS. From the analysis of Table 2 and Fig. 1, it can be concluded that the higher levels of RS were obtained when using higher Et and lower $t$, but an improvement was also found when using a low Et and a longer $t$. Comparable interaction were also found among the variables $E t$ and $T$. The optimal processing conditions for TS were: $t=2 \mathrm{~min}, T=71.9{ }^{\circ} \mathrm{C}$, $E t=100 \%$, and $S / L=5 \mathrm{~g} / \mathrm{L}$, and for RS were: $t=20 \mathrm{~min}, T=$ $176.3{ }^{\circ} \mathrm{C}, E t=0 \%$, and $S / L=41.5 \mathrm{~g} / \mathrm{L}$ (Table 3) and originated the amounts of 791.9 and $619.5 \mathrm{mg} / \mathrm{g}$ extract, respectively. The elevated $T$ was preferable for obtaining extract rich in reducing sugars, since starch and sucrose can be hydrolyzed into reducing sugars (Hui, Nip, Nollet, Paliyath, \& Simpson, 2007).

The PROT content ranged from 14.71 (run no. 22) to $78.15 \mathrm{mg} / \mathrm{g} \mathrm{E}$ (run no. 12) (Table 1 ). In general, the increase in $t, T$ and $S / L$ improved the extraction performance, while an intermediate Et (42.3\%) was favourable (Fig. 1 and Fig. 3). The response surfaces of the different variable combinations shown in Fig. 2 clearly illustrate the described trends. The effect of $t$ was linear, but the one of the other three variables was quadratic (Table 2). This may be due to the disruption of hydrogen bonds and migration of ions that enhance the solvent penetration into the matrix and release the intracellular solutes by disrupting the cell wall (Li et al., 2010), thus improving the PROT extraction. The destruction of protein-lignocellulose fraction binding may also increase the extraction. However, a $T$ higher than $146.7^{\circ} \mathrm{C}$ decreased the protein yield probably due to its denaturation. Under optimal processing conditions $\left(t=20 \mathrm{~min}, T=146.7^{\circ} \mathrm{C}, E t=42.3 \%\right.$, and $S / L=44.3 \mathrm{~g} / \mathrm{L}$; Table 3$)$ 
TS

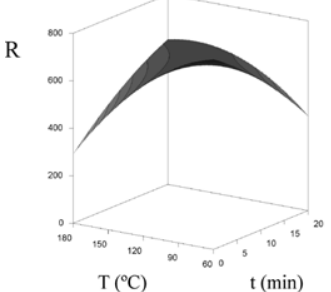

$\mathrm{R}$
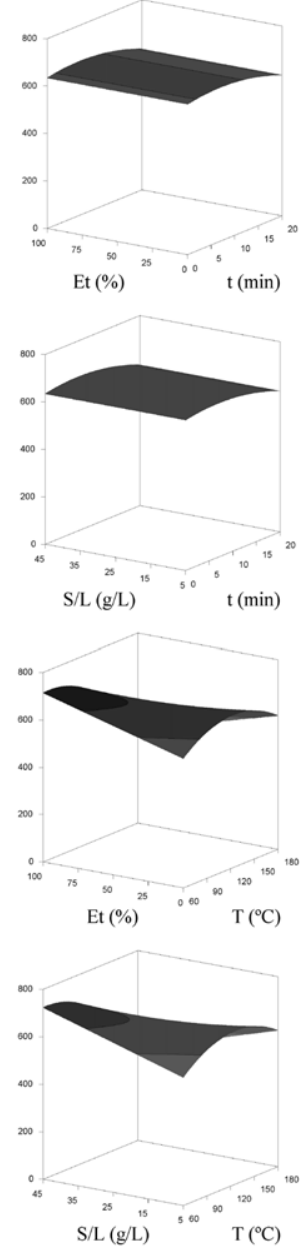

$\mathrm{R}$

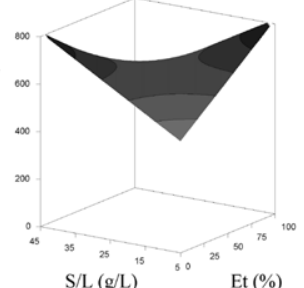

RS

R

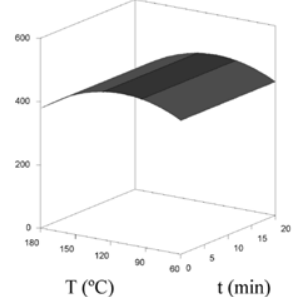

$\mathrm{R}$

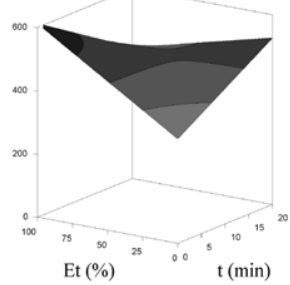

$\mathrm{R}$
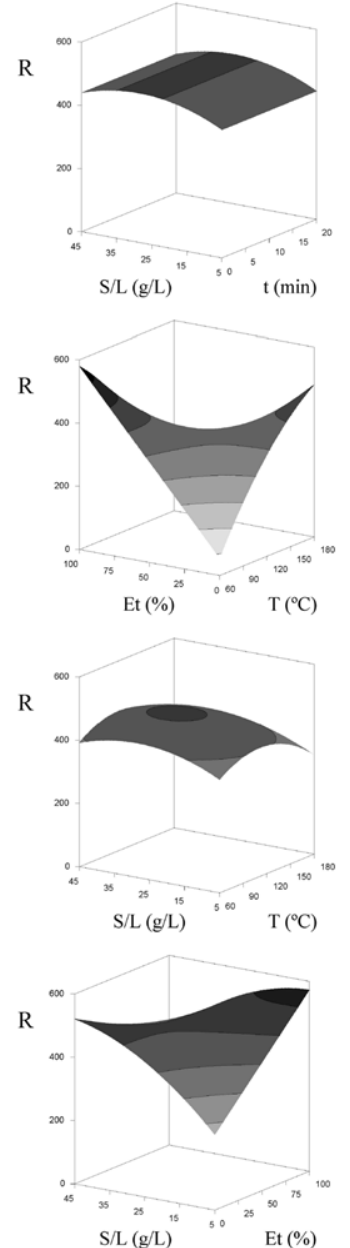

PROT

$\mathrm{R}$

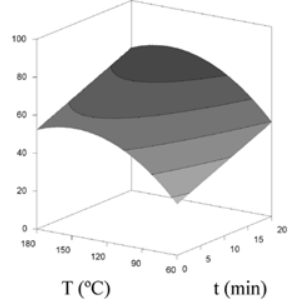

$\mathrm{R}$

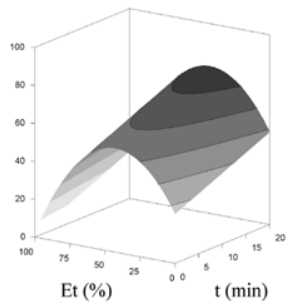

$\mathrm{R}$

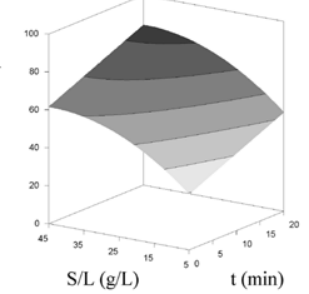

TPC

$\mathrm{R}$

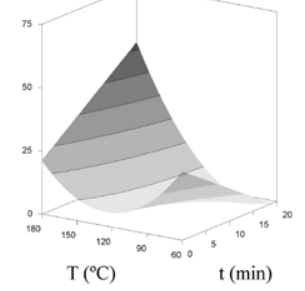

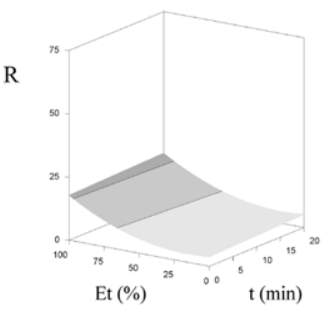
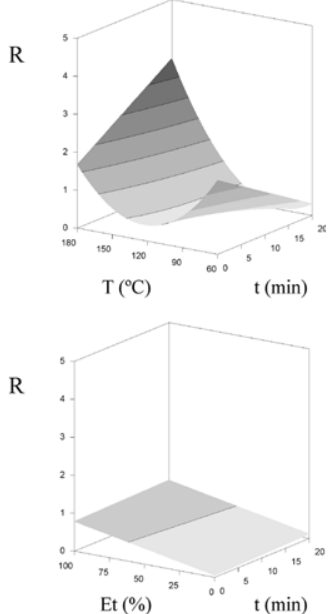

$\mathrm{R}$
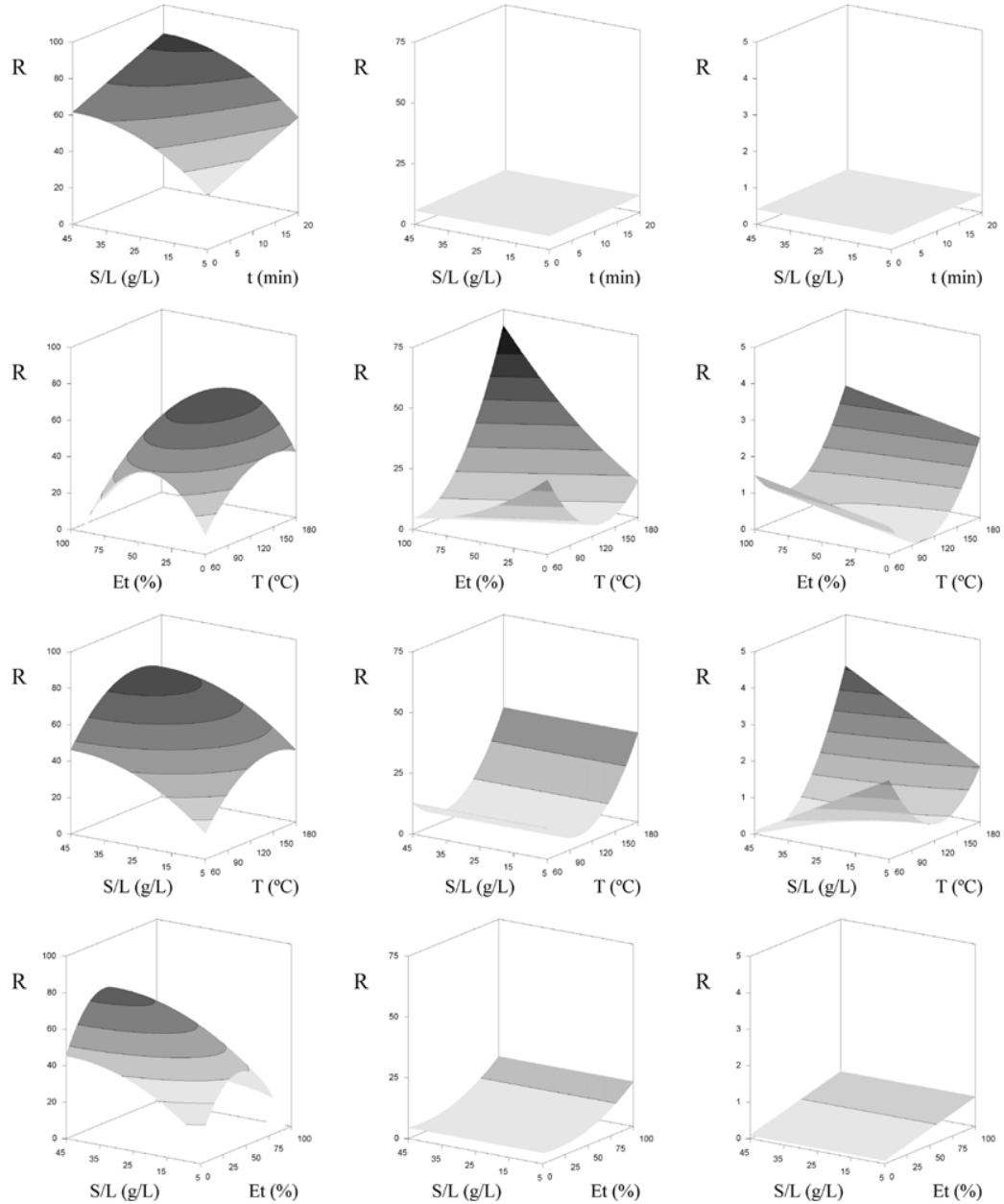

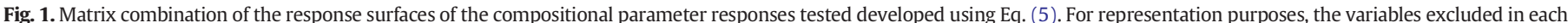

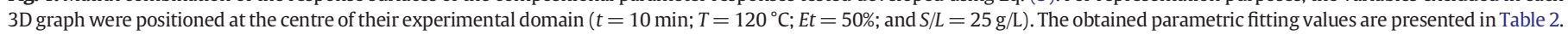

it was possible to achieve a level of $88 \mathrm{mg}$ of PROT per $\mathrm{g}$ E. In a previous study, Roselló-Soto et al. (2015) observed that the independent variable Et also significantly affects the PROT recovery from olive (Olea europaea L.) kernel samples extracted for $20 \mathrm{~min}$ and pretreated with high voltage electrical discharges. The PROT yield was higher when $25 \% \mathrm{Et}$ was used and decreased with higher percentages. The suitability of pretreatments with high voltage electrical discharges and 5 h extractions with $30 \% \mathrm{Et}$ for obtaining protein-rich extracts from blackberries (Rubus fruticosus L.) was also demonstrated by Barba et al. (2015).

The phenolic compounds are important hydrophilic constituents of tomato. In this study, the levels of TPC ranged from 4.98 to $38.63 \mathrm{mg} \mathrm{GAE} / \mathrm{g}$ E and the TFC varied from 0.16 to $2.86 \mathrm{mg} \mathrm{CE} / \mathrm{g} \mathrm{E}$ 
YIELD

$\mathrm{R}$

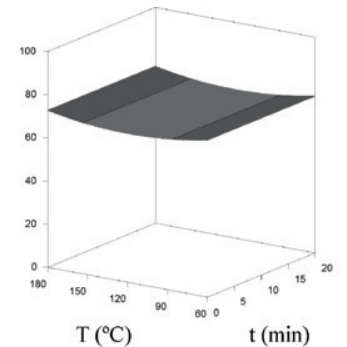

$\mathrm{R}$

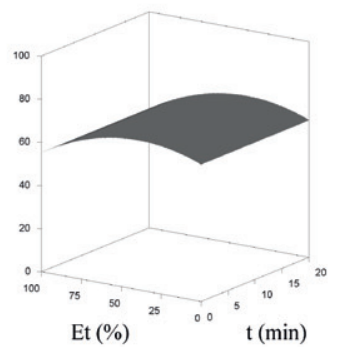

$\mathrm{R}$
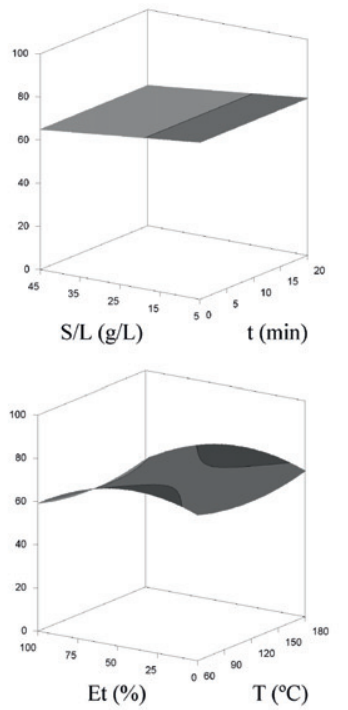

$\mathrm{R}$
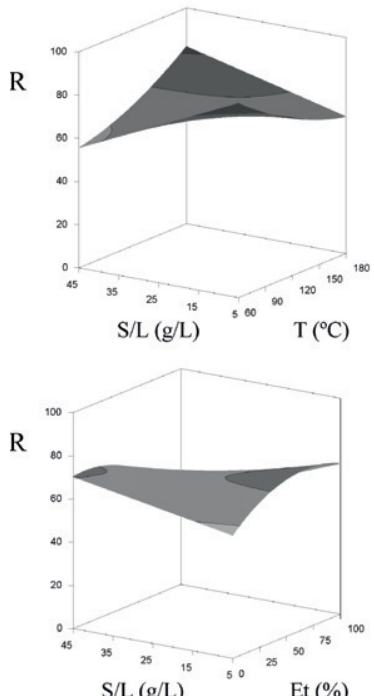

ABTS

$\mathrm{R}$
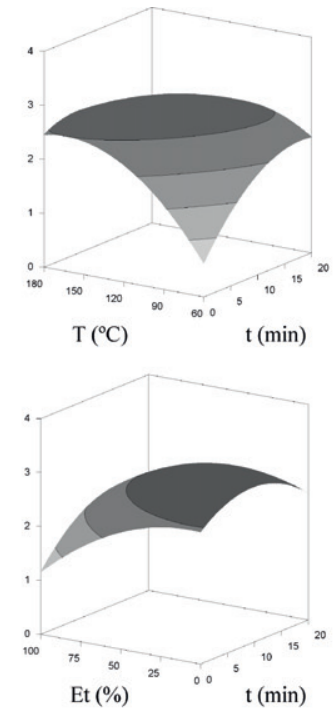

$\mathrm{R}$

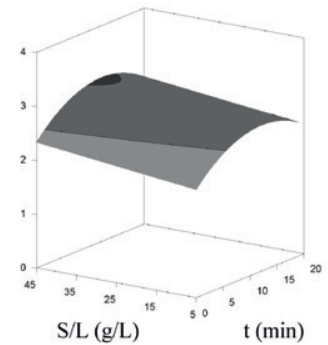

$\mathrm{R}$

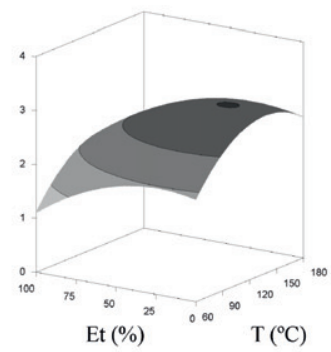

$\mathrm{R}$

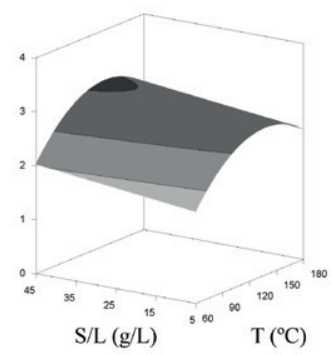

$\mathrm{R}$

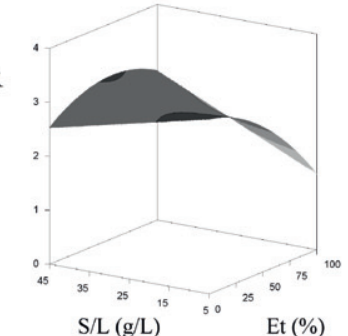

OxHLIA

$\mathrm{R}$

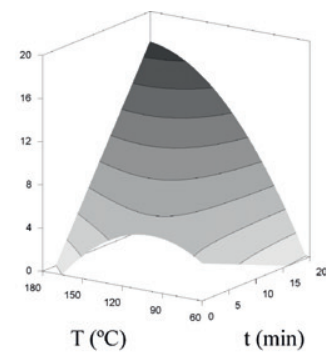

$\mathrm{R}$

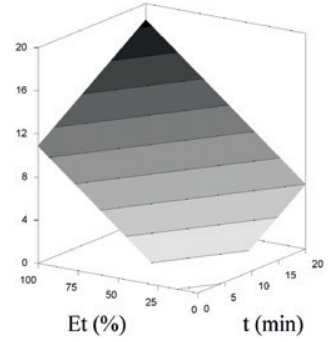

R

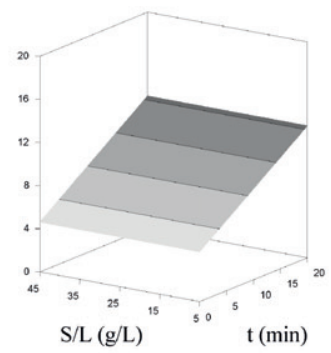

R

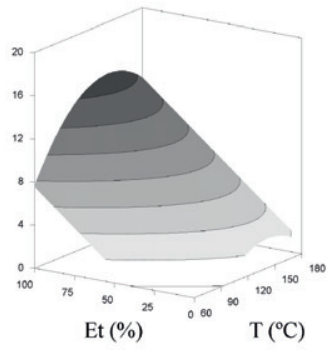

R
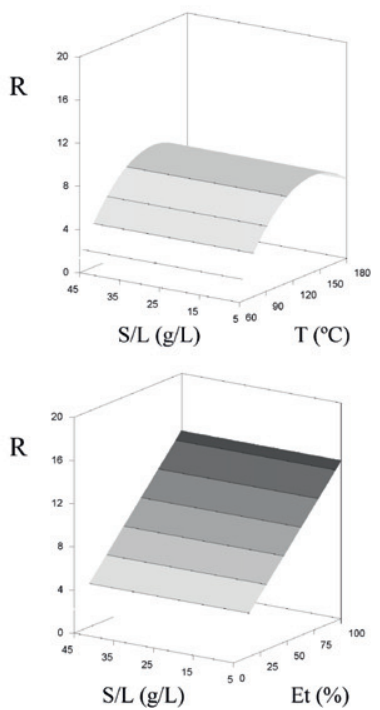

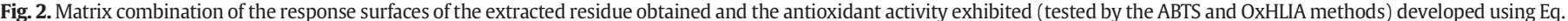

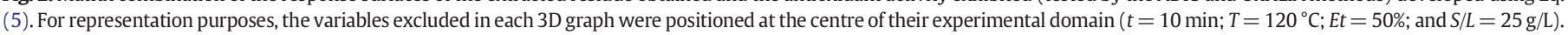
The obtained parametric fitting values are presented in Table 2. 


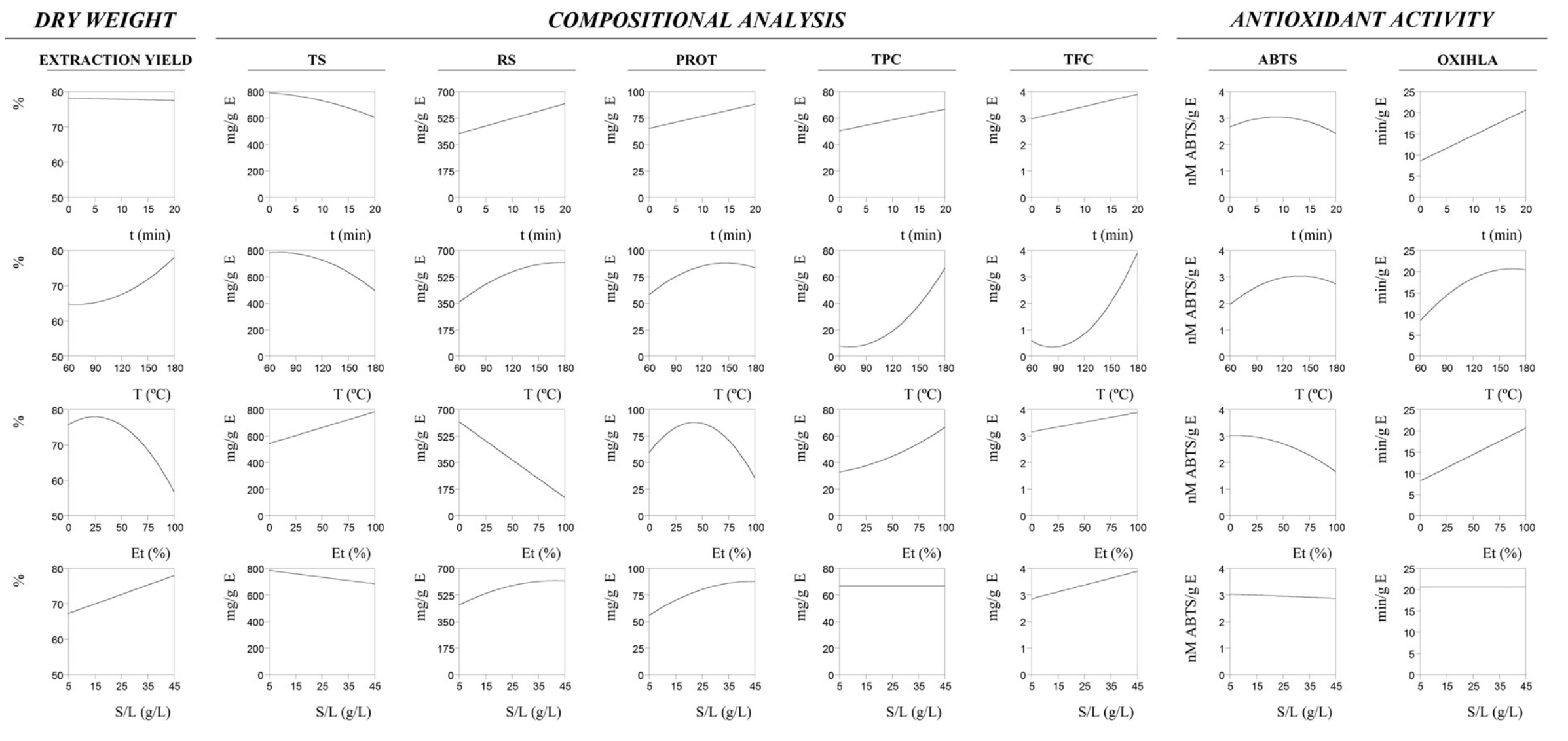

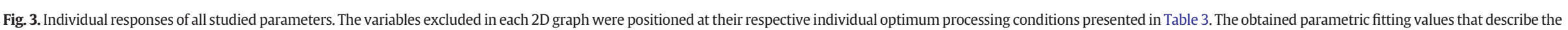
response are presented in Table 2. 
(Table 1). In both cases, the highest levels were measured in the extract obtained with the experimental run no. 20. In general, the studied independent variables had similar effects on the extraction of TPC and TFC (Fig. 2), dependent variables that were found to be significantly correlated (Table A4). The interactive effects between $T$ and $t$ are illustrated in the 3D graphs of Fig. 1 for both cases. The response was higher at increased $T$ and longer $t$, but low ranges of these variables also slightly increased the obtained response. Comparable interactive effects between $T$ and $E t$ and $T$ and $S / L$ were also found for TPC and TFC respectively. Under optimal processing conditions ( $t=20 \mathrm{~min}, T=180^{\circ} \mathrm{C}, E t=100 \%$, and $S / L=45 \mathrm{~g} / \mathrm{L}$; Table 3 ), amounts of $66.8 \mathrm{mg} \mathrm{GAE} / \mathrm{g}$ E and $3.89 \mathrm{mg} \mathrm{CE} / \mathrm{g}$ E were obtained for TPC and TFC, respectively. The significant impact of some of these independent variables on the extraction of TPC and TFC was verified in other studies using innovative technologies. Barba et al. (2015) reported that longer $t$ (up to $5 \mathrm{~h}$ ) promoted the recovery of TPC from blackberries pretreated with high voltage electrical discharges. Roselló-Soto et al. (2015) showed that the higher Et improved the extraction of TPC from olive kernel. However, degradation of TPC occurred when high voltage electrical discharges at high-energy inputs were applied. Higher Et also promoted improved responses in terms of TPC, TFC and antioxidant activity of a palm kernel byproduct extract (Wong et al., 2015). It is important to note that the Folin-Ciocalteu method used to measure TPC suffers from a number of interfering substances, such as ascorbic acid, sugars and organic acids, which may overestimate the TPC response (Lester, Lewers, Medina, \& Saftner, 2012). Nevertheless, the TPC detected in the tomato waste extracts was not found correlated with TS or RS (Table A4).

3.2.3.3. Antioxidant activity. The results of the antioxidant activity of the different tomato waste extracts are presented in Table 1 . While the ABTS ${ }^{+}$scavenging activity was higher when lower Et (3.4\%) and $S / L$ $(5 \mathrm{~g} / \mathrm{L})$ were used, the OxHLIA exhibited a better performance at higher levels of these variables ( $E t=100 \%$ and $S / L=45 \mathrm{~g} / \mathrm{L}$ ) (Fig. 3). However, the variable $S / L$ did not had a significant effect on the inhibition of free radical-induced membrane damage in the sheep erythrocytes (Table 2 ). The higher $T$ had a positive impact on the antioxidant properties. Interesting to note the interactive effects between the variables $t$ and $T$; the extracts submitted to a longer processing $t$ ( $20 \mathrm{~min}$ ) and a higher $T\left(164.2^{\circ} \mathrm{C}\right)$ revealed increased OxHLIA responses; and the ABTS ${ }^{+}$scavenging activity was detachable in extract obtained with shorter processing $t$ and high $T$, and vice versa. In this assay there were other interactive effects, namely between $t$ and $E t$ and $E t$ and $S / L$. The optimum processing conditions (Table 3 ) to obtain extracts with an improved ABTS • ${ }^{+}$ scavenging activity were as follow: $t=8.75 \mathrm{~min}, T=138.5^{\circ} \mathrm{C}, \mathrm{Et}=$ $3.4 \%$, and $S / L=5 \mathrm{~g} / \mathrm{L}$. In turn, the processing conditions of $t=20 \mathrm{~min}$, $T=164.2^{\circ} \mathrm{C}, E t=100 \%$, and $S / L=45 \mathrm{~g} / \mathrm{L}$ originated extracts with a high capacity to prevent the free radical-induced membrane damage in sheep erythrocytes.

3.2.3.4. Antioxidant activity of tomato waste extracts vs. commercial antioxidants. Different antioxidant compounds have been used as food additives to prevent oxidative deterioration processes (Carocho, Barreiro, Morales, \& Ferreira, 2014). However, due to limitation on the use of synthetic antioxidants and enhanced public awareness of health issues, there is an increasing need to develop and use health-promoting natural antioxidant ingredients in foods (Carocho et al., 2015). In this study, the antioxidant activity of the extracts was compared to the activity of commercial antioxidants communally used in the food industry. Table A3 provided in Supplementary material presents the obtained parametric fitting values for the evaluated antioxidants. The synthetic antioxidants TBHQ and ETX revealed the highest oxidative haemolysis inhibition capacity ( 844.1 and $728.2 \mathrm{~min} / \mathrm{mg} \mathrm{A}$, respectively). In the ABTS assay, the higher ABTS ${ }^{+}$scavenging activity was demonstrated by the antioxidants TBHQ and PG (0.050 and $0.097 \mathrm{nM} \mathrm{ABTS/g} \mathrm{A,} \mathrm{respectively).}$
Despite the antioxidant activity of the extracts is much lower compared with the evaluated commercial antioxidants, it is important to note that these tomato waste extracts are composed of different biomolecules while the commercial antioxidants are isolated pure compounds.

\subsection{Global MAE conditions that maximize all responses}

Optimal MAE conditions were determined for production of tomato waste ingredients with high levels of all nutrients or with high antioxidant properties, as well as global MAE conditions for maximizing all evaluated responses and thus obtaining nutrient-rich antioxidant ingredients. Under the global optimal MAE conditions $(t=20 \mathrm{~min}, T=$ $180^{\circ} \mathrm{C}, \mathrm{Et}=47.4 \%$ and $\mathrm{S} / \mathrm{L}=45 \mathrm{~g} / \mathrm{L}$ ), it was possible to obtain a extraction yield of $75.5 \%$ and ingredients with $480.3 \mathrm{mg} / \mathrm{g} \mathrm{E}$ of TS, $361.2 \mathrm{mg} / \mathrm{g} \mathrm{E}$ of RS, $83.2 \mathrm{mg} / \mathrm{g}$ E of PROT, $43.9 \mathrm{mg}$ GAE/g E of TPC and $3.5 \mathrm{mg} \mathrm{CE} / \mathrm{g} \mathrm{E}$ and a ABTS ${ }^{+}$scavenging activity of $2.2 \mathrm{nM}$ ABTS/g E and OxHLIA inhibition of $13.8 \mathrm{~min} / \mathrm{g}$ E. Based on these optimized processing parameters it will be possible to produce food ingredients with different properties according to the intended purpose (with high levels of nutrients, increased antioxidant properties, or both) and thus give value to tomato fruit wastes. These results are in line with those previously reported by Pinela et al. (2016b). The authors verified that the global optimum MAE conditions for obtained tomato extracts rich in the major phenolic acids (benzyl alcohol dihexose and a cis p-coumaric acid derivative) and flavonoids (quercetin pentosylrutinoside and quercetin-3-Orutinoside) and with antioxidant properties (measured via DPPH freeradical scavenging activity and reducing power) were based on a high processing $t$ of $20 \mathrm{~min}, T$ of $180{ }^{\circ} \mathrm{C}$ and $S / L$ of $45 \mathrm{~g} / \mathrm{L}$, in agreement with the results of this study. However, water was the most suitable extraction solvent.

\section{Conclusions}

The valorisation of tomato wastes for production of nutrient-rich antioxidant ingredients is a sustainable strategy that can contributes to a bio-economy and helps to tackle the societal challenges of this century. In fact, this study addresses modern concepts of green chemistry, namely the recycling of agri-food wastes and the use of more sustainable extraction methods. Despite the moderate capital cost of commercial microwave systems (Galanakis, Barba, \& Prasad, 2015), MAE allowed obtain high extraction yields and reduce the solvent consumption. The developed MAE process was designed based on a CCCD combining different levels of $t, T, E t$ and S/L, which were optimized by RSM. The proposed model was validated based on the high values of $\mathrm{R}^{2}$ adj and on the non-significant differences between experimental and predicted values. Optimal MAE conditions were calculated for each of the eight dependent variables, for the set of compositional parameters and antioxidant activities, as well as for all studied responses, which will allow producing extracts with the desired compositional/antioxidant profiles. The antioxidant capacity of the extracts of tomato fruit waste was lower than the one of commercial antioxidants widely used in the food industry. However, the developed ingredients presented potential to be used in the fortification and functionalisation of food, or be incorporated in feed products.

\section{Conflict of interest}

Authors declare no conflict of interest.

\section{Acknowledgments}

The authors are grateful to the Foundation for Science and Technology (FCT) (UID/AGR/00690/2013, UID/QUI/50006/2013 - POCI/01/ 0145/FERDER/007265, UID/EQU/50020/2013) and (SFRH/BD/92994/ 2013) of Portugal and FEDER for financial support to CIMO (UID/AGR/ 00690/2013); to FCT/MEC for financial support to REQUIMTE/LAQV 
(UID/QUI/50006/2013 - POCI/01/0145/FERDER/007265) and LSRE (UID/EQU/50020/2013) through national funds and co-financed by FEDER under Programme PT2020, and to QREN, ON2 and FEDER (Project NORTE-07-0162-FEDER-000050); to FCT for the PhD scholarship (SFRH/BD/92994/2013) attributed to J. Pinela, funded by the European Social Fund and MEC through Programa Operacional Capital Humano (POCH); to the Xunta de Galicia for financial support for the post-doctoral researcher of M.A. Prieto; and to Araceli Menduiña Santomé for her professional work and dedication.

\section{Appendix A. Supplementary data}

Supplementary data to this article can be found online at http://dx. doi.org/10.1016/j.ifset.2017.02.004.

\section{References}

Albuquerque, B. R., Prieto, M. A., Barreiro, M. F., Rodrigues, A., Curran, T. P., Barros, L., \& Ferreira, I. C. F. R. (2017). Catechin-based extract optimization obtained from Arbutus unedo L. fruits using maceration/microwave/ultrasound extraction techniques. Industrial Crops and Products, 95, 404-415.

Barba, F. J., Galanakis, C. M., Esteve, M. J., Frigola, A., \& Vorobiev, E. (2015). Potential use of pulsed electric technologies and ultrasounds to improve the recovery of high-added value compounds from blackberries. Journal of Food Engineering, 167, 38-44.

Barros, L., Carvalho, A. M., Morais, J. S., \& Ferreira, I. C. F. R. (2010). Strawberry-tree, blackthorn and rose fruits: Detailed characterisation in nutrients and phytochemicals with antioxidant properties. Food Chemistry, 120(1), 247-254.

Barros, L., Dueñas, M., Pinela, J., Carvalho, A. M., Buelga, C. S., \& Ferreira, I. C. F. R. (2012). Characterization and quantification of phenolic compounds in four tomato (Lycopersicon esculentum L.) farmers' varieties in northeastern Portugal homegardens. Plant Foods for Human Nutrition (Dordrecht, Netherlands), 67(3), 229-234.

Bernfeld, P. (1951). Enzymes of starch degradation and synthesis. Advances in Enzymology and Related Areas of Molecular Biology, 12, 379-428.

Bezerra, M. A., Santelli, R. E., Oliveira, E. P., Villar, L. S., \& Escaleira, E. A. (2008). Response surface methodology (RSM) as a tool for optimization in analytical chemistry. Talanta, 76, 965-977.

Box, G. E. P., \& Hunter, J. S. (1957). Multi-factor experimental designs for exploring response surfaces. The Annals of Mathematical Statistics, 28(1), 195-241.

Box, G., Hunter, J., \& Hunter, W. (2005). Statistics for experimenters: Design, innovation and discovery (2nd ed.). Wiley.

Carocho, M., Barreiro, M. F., Morales, P., \& Ferreira, I. C. F. R. (2014). Adding molecules to food, pros and cons: A review on synthetic and natural food additives. Comprehensive Reviews in Food Science and Food Safety, 13(4), 377-399.

Carocho, M., Morales, P., \& Ferreira, I. C. F. R. (2015). Natural food additives: Quo vadis? Trends in Food Science E Technology, 45(2), 284-295.

Comuzzi, C., Polese, P., Melchior, A., Portanova, R., \& Tolazzi, M. (2003). SOLVERSTAT: A new utility for multipurpose analysis. An application to the investigation of dioxygenated Co (II) complex formation in dimethylsulfoxide solution. Talanta, 59(1), 67-80.

Deng, Q., Zinoviadou, K. G., Galanakis, C. M., Orlien, V., Grimi, N., Vorobiev, E., ... Barba, F. J. (2015). The effects of conventional and non-conventional processing on glucosinolates and its derived forms, isothiocyanates: Extraction, degradation, and applications. Food Engineering Reviews, 7(3), 357-381.

Dubois, M., Gilles, K. A., Hamilton, J. K., Rebers, P. A., \& Smith, F. (1956). Colorimetric method for determination of sugars and related substances. Analytical Chemistry, 28(3), 350-356

FAO (2013). Food wastage footprint. Impacts on natural resources. Summary report. Food wastage footprint impacts on natural resources. Food and Agriculture Organization.

Galanakis, C. M. (2012). Recovery of high added-value components from food wastes: Conventional, emerging technologies and commercialized applications. Trends in Food Science \& Technology, 26(2), 68-87.

Galanakis, C. M. (2013). Emerging technologies for the production of nutraceuticals from agricultural by-products: A viewpoint of opportunities and challenges. Food and Bioproducts Processing, 91(4), 575-579.

Galanakis, C. M., Barba, F. J., \& Prasad, K. N. (2015). Cost and safety issues of emerging technologies against conventional techniques. In C. M. Galanakis (Ed.), Food waste recovery (pp. 321-336). Academic Press.

Gieseg, S. P., \& Esterbauer, H. (1994). Low density lipoprotein is saturable by pro-oxidant copper. FEBS Letters, 343(3), 188-194

Havilah, E. J., Wallis, D. M., Morris, R., \& Woolnough, J. A. (1977). A microcolorimetric method for determination of ammonia in Kjeldahl digests with a manual spectrophotometer. Laboratory Practice, 26, 545-547.

Heleno, S. A., Diz, P., Prieto, M. A., Barros, L., Rodrigues, A., Barreiro, M. F., \& Ferreira, I. C. F. R. (2016). Optimization of ultrasound-assisted extraction to obtain mycosterols from Agaricus bisporus L. by response surface methodology and comparison with conventional Soxhlet extraction. Food Chemistry, 197, 1054-1063.

Hui, Y. H., Nip, W. K., Nollet, L. M. L., Paliyath, G., \& Simpson, B. K. (2007). Food biochemistry and food processing. Blackwell Publishing.
Kemmer, G., \& Keller, S. (2010). Nonlinear least-squares data fitting in Excel spreadsheets Nature Protocols, 5(2), 267-281.

Kim, S. P., Nam, S. H., \& Friedman, M. (2015). The tomato glycoalkaloid $\alpha$-tomatine induces caspase-independent cell death in mouse colon cancer CT-26 cells and transplanted tumors in mice. Journal of Agricultural and Food Chemistry, 63(4), 1142-1150.

Lester, G. E., Lewers, K. S., Medina, M. B., \& Saftner, R. A. (2012). Comparative analysis of strawberry total phenolics via Fast Blue BB vs. Folin-Ciocalteu: Assay interference by ascorbic acid. Journal of Food Composition and Analysis, 27(1), 102-107.

Li, J., Zu, Y. -G., Fu, Y. -J., Yang, Y. -C., Li, S. -M., Li, Z. -N., \& Wink, M. (2010). Optimization of microwave-assisted extraction of triterpene saponins from defatted residue of yellow horn (Xanthoceras sorbifolia Bunge.) kernel and evaluation of its antioxidant activity. Innovative Food Science E Emerging Technologies, 11(4), 637-643.

Li, H., Deng, Z., Liu, R., Loewen, S., \& Tsao, R. (2014). Bioaccessibility, in vitro antioxidant activities and in vivo anti-inflammatory activities of a purple tomato (Solanum lycopersicum L.). Food Chemistry, 159, 353-360.

Murado, M. A., \& Prieto, M. A. (2013). Dose-response analysis in the joint action of two effectors. A new approach to simulation, identification and modelling of some basic interactions. PLoS ONE, 8(4), e61391.

Pereira, C., Barros, L., Carvalho, A. M., \& Ferreira, I. C. F. R. (2011). Nutritional composition and bioactive properties of commonly consumed wild greens: Potential sources for new trends in modern diets. Food Research International, 44(9) 2634-2640.

Pinela, J., Barros, L., Carvalho, A. M., \& Ferreira, I. C. F. R. (2012). Nutritional composition and antioxidant activity of four tomato (Lycopersicon esculentum L.) farmers' varieties in Northeastern Portugal homegardens. Food and Chemical Toxicology, 50(3-4) 829-834.

Pinela, J., Prieto, M. A., Barreiro, M. F., Carvalho, A. M., Oliveira, M. B. P. P., Vázquez, J. A., \& Ferreira, I. C. F. R. (2016a). Optimization of microwave-assisted extraction of hydrophilic and lipophilic antioxidants from a surplus tomato crop by response surface methodology. Food and Bioproducts Processing, 98, 283-298.

Pinela, J., Prieto, M. A., Carvalho, A. M., Barreiro, M. F., Oliveira, M. B. P. P., Barros, L., \& Ferreira, I. C. F. R. (2016b). Microwave-assisted extraction of phenolic acids and flavonoids and production of antioxidant ingredients from tomato: A nutraceutical-oriented optimization study. Separation and Purification Technology, 164 $114-124$

Pinela, J., Oliveira, M. B. P. P., \& Ferreira, I. C. F. R. (2016c). Bioactive compounds of tomatoes as health promoters. In L. R. da Silva, \& B. Silva (Eds.), Natural bioactive compounds from fruits and vegetables as health promoters. 2. (pp. 48-91). Bentham Science Publishers (Chapter 3).

Prieto, M. A., \& Vázquez, J. A. (2014). A time-dose model to quantify the antioxidant responses of the oxidative hemolysis inhibition assay (OxHLIA) and its extension to evaluate other hemolytic effectors. BioMed Research International, 2014 15-17.

Prieto, M. A., Vázquez, J. A., \& Murado, M. A. (2014). A critical point: The problems associated with the variety of criteria to quantify the antioxidant capacity. Journal of Agricultural and Food Chemistry, 62(24), 5472-5484.

Prieto, M., Curran, T., Gowen, A., \& Vázquez, J. (2015). An efficient methodology for quantification of synergy and antagonism in single electron transfer antioxidant assays. Food Research International, 67, 284-298.

Prikler, S. (2009). Robert de Levie: Advanced Excel for scientific data analysis (2nd ed) Analytical and Bioanalytical Chemistry, 395, 1945-1964.

Ravindran, R., \& Jaiswal, A. K. (2016). Exploitation of food industry waste for high-value products. Trends in Biotechnology, 34(1), 58-69.

Riggi, E., \& Avola, G. (2008). Fresh tomato packinghouses waste as high added-value biosource. Resources, Conservation and Recycling, 53(1-2), 96-106.

Roselló-Soto, E., Barba, F. J., Parniakov, O., Galanakis, C. M., Lebovka, N., Grimi, N., \& Vorobiev, E. (2015). High voltage electrical discharges, pulsed electric field, and ultrasound assisted extraction of protein and phenolic compounds from olive kernel. Food and Bioprocess Technology, 8(4), 885-894.

Serpen, A., Capuano, E., Fogliano, V., \& Gökmen, V. (2007). A new procedure to measure the antioxidant activity of insoluble food components. Journal of Agricultural and Food Chemistry, 55(19), 7676-7681.

Setyaningsih, W., Saputro, I. E., Palma, M., \& Barroso, C. G. (2016). Pressurized liquid extraction of phenolic compounds from rice (Oryza sativa) grains. Food Chemistry, 192, 452-459.

Shi, P., \& Tsai, C. -L. (2002). Regression model selection: A residual likelihood approach. Journal of the Royal Statistical Society. Series B (Statistical Methodology), 64(2), 237-252.

Stajčić, S., Ćetković, G., Čanadanović-Brunet, J., Djilas, S., Mandić, A., \& Četojević-Simin, D. (2015). Tomato waste: Carotenoids content, antioxidant and cell growth activities. Food Chemistry, 172, 225-232.

Strati, I. F., \& Oreopoulou, V. (2014). Recovery of carotenoids from tomato processing byproducts - A review. Food Research International, 65, 311-321.

Takebayashi, J., Kaji, H., Ichiyama, K., Makino, K., Gohda, E., Yamamoto, I., \& Tai, A (2007). Inhibition of free radical-induced erythrocyte hemolysis by 2-0substituted ascorbic acid derivatives. Free Radical Biology and Medicine, 43(8), 1156-1164.

Takebayashi, J., Iwahashi, N., Ishimi, Y., \& Tai, A. (2012). Development of a simple 96-well plate method for evaluation of antioxidant activity based on the oxidative haemolysis inhibition assay (OxHLIA). Food Chemistry, 134(1), 606-610.

Vilahur, G., Cubedo, J., Padró, T., Casaní, L., Mendieta, G., González, A., \& Badimon, L. (2014). Intake of cooked tomato sauce preserves coronary endothelial function and 
improves apolipoprotein A-I and apolipoprotein J protein profile in high-density lipoproteins. Translational Research, 44-56.

Weibull, W., \& Sweden, S. (1951). A statistical distribution function of wide applicability Journal of Applied Mechanics, 18(3), 293-297.

Wong, W. H., Lee, W. X., Ramanan, R. N., Tee, L. H., Kong, K. W., Galanakis, C. M., ... Prasad, K. N. (2015). Two level half factorial design for the extraction of phenolics, flavonoids and antioxidants recovery from palm kernel by-product. Industrial Crops and Products, 63, 238-248.

Zhang, H. -F., Yang, X. -H., \& Wang, Y. (2011). Microwave assisted extraction of secondary metabolites from plants: Current status and future directions. Trends in Food Science E' Technology, 22(12), 672-688. 